\title{
Benchmark
}

\section{Tracing the Origin of Non-Hematopoietic Cells Using CD45 PCR Restriction Fragment Length Polymorphisms}

BioTechniques 34:160-162 (January 2003)

\section{Carlos A. Ramos, Yayun Zheng, Ilyas Colombowala, and Margaret A. Goodell \\ Baylor College of Medicine, Houston, TX, USA}

The possibility of distinguishing the product of different CD45 alleles by immunocytochemistry has made this antigenic system a popular way of tracking the origin of hematopoietic cells in congenic models of transplantation, in which the animals diverge only in their CD45 alleles (15). The extracellular domains of the transmembrane phosphatases encoded by each allele differ in three amino acid residues, which generates distinct epitopes that are recognizable by specific antibodies $(3,5,10)$. Yet, the fact that those antigens are expressed only in cells of hematopoietic origin precludes the use of the same approach to study nonhematopoietic organs. Several recent reports of transdifferentiation of hematopoietic cells into other tissues $(1,2,4,6-8)$ highlight the relevance of having a simple way of assessing the occurrence of this phenomenon, by investigating the presence in various organs of non-hematopoietic cells that carry the donor CD45 allele. We present a method that exploits the existence of differences in restriction sites among CD45 alleles to allow tracking the origin of cells contributing to non- hematopoietic organs.

The gene encoding the CD45 antigen [also known as leucocyte common antigen (LCA), protein tyrosine phosphatase receptor-type c polypeptide (Ptprc), or Ly5] maps to chromosome 1 (16) and comprises 34 exons $(13,14)$. Exons $1 \mathrm{a}$ and $1 \mathrm{~b}$ are untranslated and alternatively excluded. Exons 4 (also known as A), 5 (B), and 6 (C) can be alternatively spliced, giving rise to different cell type specific isoforms, which can also be recognized by distinct antibodies (CD45RA, RB, RC, and RO) that react across allelic variants (10-12).

Hitherto, three murine CD45 alleles have been documented: CD45.1 (Ly5.1 or Ly5a), CD45.2 (Ly5.2 or Ly5b), and CD45.3 (Ly5.3 or Ly5c). Of note, the nomenclature for alleles 1 and 2 was reversed in 1987 (9), which is still a source of confusion. Most murine strains, such as $\mathrm{BALB} / \mathrm{c}, \mathrm{C} 57 \mathrm{Bl} / 6$, $\mathrm{CBA}$, and NZB/BLN, originally expressed the CD45.2 allele, while CD45.1 was present in SJL mice. However, inbred strains have been backcrossed to carry another CD45 allele $(5,17)$, notably the C57Bl/6 line, commonly used for bone marrow transplant experiments involving CD45.1 and CD45.2 mismatch. In contrast to the extracellular portion, the cytoplasmic domain is conserved in both CD45.1 and CD45.2 proteins, but its coding sequence has two silent nucleotide changes that are responsible for two restriction site differences between alleles (Figure 1). The CD45.1 gene has a unique $X$ hoI site at codon 738 (exon 23 ), and the CD45.2 gene has a unique $K p n I$ site at codon 825 (exon 25) (17).

To be able to generate DNA segments by PCR of sufficient size to be resolved in an agarose gel, we required some knowledge about the intronic sequences. Although all CD45 exons have been sequenced so far, there is no information about CD45 introns in public genomic databases. Therefore, we first sequenced the introns adjacent to the exons containing the relevant restriction sites. The sequences were read at Baylor College of Medicine core sequencing facility and deposited in GenBank ${ }^{\circledR}$ (accession nos. AY090071-AY090075 and AY096794-AY096795).

After sequencing the introns of interest, primers were designed to anneal to sequences around the $X h o \mathrm{I}$ and the $K p n \mathrm{I}$ restriction sites (XhoI FWD: 5'TGTGATAATCCTTTTTGCAGTCTTCTT-3' - in intron 22-and XhoI REV: 5'-GTTTTAGTTCCTCACATTTTACATTCCTTA-3' - intron 23; KpnI FWD-3: 5'-TAGTATGGAGGAGAGCTTTATTGAG-3' - intron 24-and KpnI REV: 5'-TCCACTTGCACCATCAGACACC-3' - exon 25) (Figure 1). PCR was performed on template DNA samples (approximately $10 \mu \mathrm{g}$ ) obtained from mixing different proportions of CD45.1 and CD45.2 bone marrow cells (Figure 1 ) in a $100-\mu \mathrm{L}$ solution containing $10 \mathrm{U}$ Taq DNA polymerase (Invitrogen, Carlsbad, CA, USA) and $20 \mathrm{mM}$ Tris- $\mathrm{HCl}$ (pH 8.4), 50 $\mathrm{mM} \mathrm{KCl}, 1.5 \mathrm{mM} \mathrm{MgCl}_{2}, 0.2 \mathrm{mM}$ 
dATP, $0.2 \mathrm{mM}$ dCTP, $0.2 \mathrm{mM}$ dGTP, $0.2 \mathrm{mM}$ dTTP, and $0.4 \mu \mathrm{M}$ each primer. PCR conditions were the following: 3 min initial denaturation at $94^{\circ} \mathrm{C} ; 36 \mathrm{cy}-$ cles of $1 \mathrm{~min}$ at $94^{\circ} \mathrm{C}, 30 \mathrm{~s}$ at $58^{\circ} \mathrm{C}$ and
$30 \mathrm{~s}$ at $72^{\circ} \mathrm{C} ; 10 \mathrm{~min}$ elongation at $72^{\circ} \mathrm{C}$. Each of the reactions was digested with $100 \mathrm{U}$ of the corresponding restriction enzyme (XhoI: New England Biolabs, Beverly, MA, USA; and KpnI:

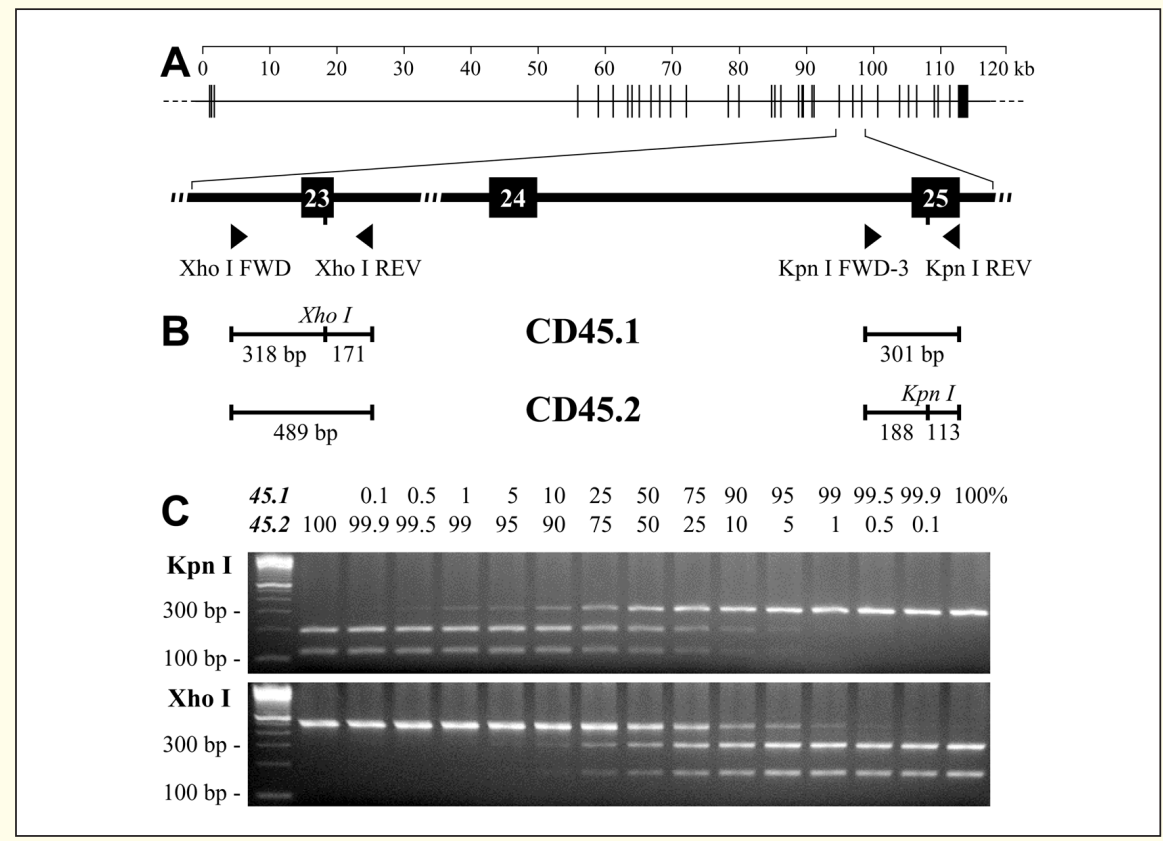

Figure 1. Restriction digestion of genomic CD45 PCR amplified segments. (A) Molecular map of $C D 45$ with close-up of the regions containing the restriction sites of interest. The boxes represent the exons, and the lines correspond to the introns. The numbers inside the boxes identify the exons. The small vertical lines extending from exons 23 and 25 show the restriction site locations, and the triangles illustrate the position of the primers used for our assay. (B) Depiction of the fragments obtained after digestion of the PCR products according to the respective allele. (C) 3.2\% agarose gel electrophoresis of the fragments obtained after digestion of the PCR products with the corresponding restriction enzyme. Each lane corresponds to a different proportion of CD 45.1 and CD 45.2 bone marrow cells, as noted above the gel photograph.

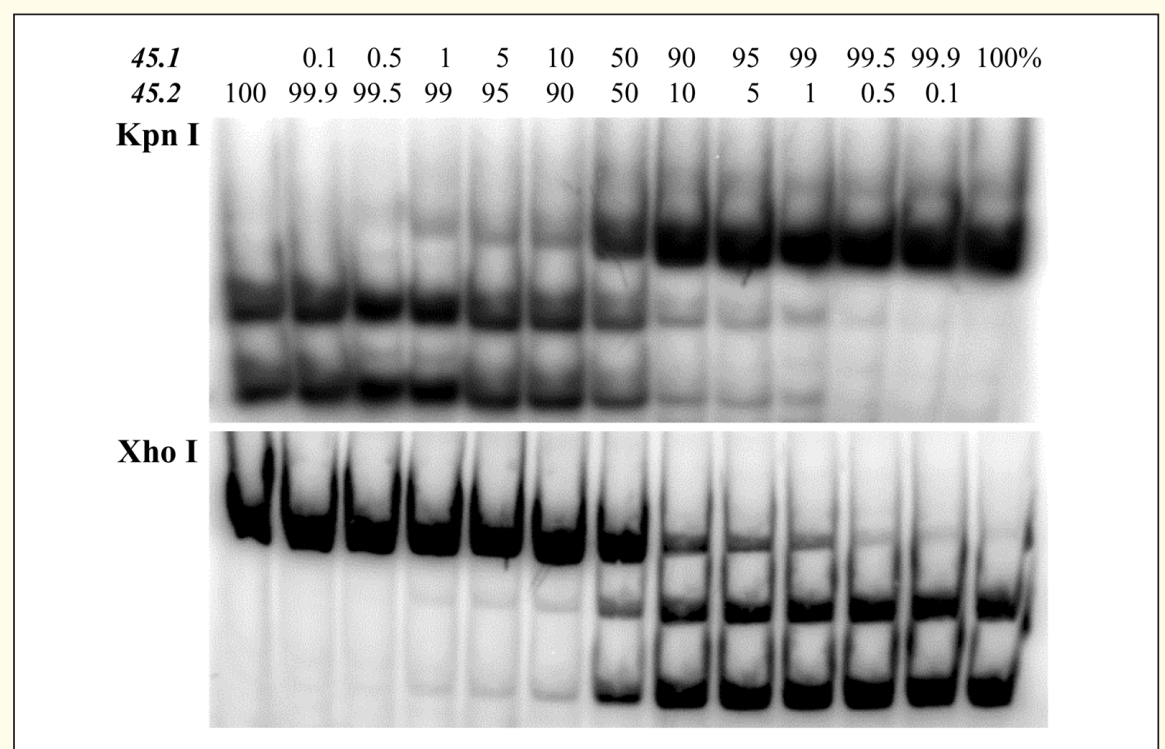

Figure 2. Restriction digestion of genomic CD45 amplified segments with radioactive labeling of primers. The method used in the experiment represented in Figure 1A was combined with radioactive labeling of primers. The sensitivity of the technique improves about 10-fold.
Promega, Madison, WI, USA), $24 \mu \mathrm{L}$ $10 \times$ buffer, $2.4 \mu \mathrm{L} 10 \mathrm{mg} / \mathrm{mL}$ BSA (Promega, Madison, WI, USA), and water to a final volume of $240 \mu \mathrm{L}$ for 16 $\mathrm{h}$ at $37^{\circ} \mathrm{C}$. These digestion products and an equivalent amount of the undigested segments were concentrated to $40 \mu \mathrm{L}$ with a SpeedVac ${ }^{\circledR}$ machine (Jouan, Winchester, VA, USA) and run on the same $3.2 \%$ agarose gel (Invitrogen).

To increase the sensitivity of our method when one of the alleles was less than $1 \%$ of the mixture, the same PCR and restriction digestions were replicated, but the primers were radioactively labeled in a $20-\mu \mathrm{L}$ reaction containing $50 \mathrm{U}$ T4 polynucleotide kinase (Invitrogen), $30 \mu \mathrm{M}$ primer, $70 \mathrm{mM}$ Tris- $\mathrm{HCl}$ (pH 7.6), $10 \mathrm{mM} \mathrm{MgCl}_{2}, 100 \mathrm{mM} \mathrm{KCl}$, $1 \mathrm{mM}$ 2-mercaptoethanol, and $417 \mathrm{nM}$ $\gamma\left[{ }^{32} \mathrm{P}\right]$ ATP $(6 \mathrm{kCi} / \mathrm{mmol})$ (Amersham Biosciences, Piscataway, NJ, USA). The digestion reaction was concentrated to $100 \mu \mathrm{L}$ with a SpeedVac machine and run on a $5 \%$ polyacrylamide gel (Bio-Rad Laboratories, Hercules, CA, USA). The gel was dried and exposed on a storage phosphor screen, which was read by a Storm ${ }^{\mathrm{TM}} 860$ scanner (both from Molecular Dynamics, Sunnyvale, CA, USA).

Regardless of the genotype, PCR with XhoI FWD/REV and KpnI FWD3/REV primers leads to amplification of 489- and 301-bp segments, respectively (Figure 1). After digestion of the 489-bp PCR product with XhoI, two fragments of 318 and $171 \mathrm{bp}$ are obtained for the CD45.1 allele, while the CD45.2 allele remains intact. Digestion of the 301-bp PCR product with $K p n I$ yields two fragments of 188 and $113 \mathrm{bp}$ for the CD45.2 allele, whereas no change is noted on the CD45.1 allele. The pattern of digestion of both fragments thus constitutes a signature for each of the alleles. Under the conditions used, the digestions, as assessed by ethidium bromide staining or radioactive labeling, are complete (Figures 1 and 2).

In reactions performed on mixed cell aliquots, incubation of each of the PCR products with the respective restriction enzyme yields a mixture of intact segments and digested fragments with the sizes described above (Figure $1)$. The relative intensity of digested versus undigested molecules depends 
on the relative amount of each allele and the sizes of the fragments. The use of complementary restriction sites serves as an internal control for these experiments. Since digestions are complete, the presence of undigested fragments always indicates that there is a mixture of CD45 alleles present. The sensitivity of the method when combined with radioactive labeling of primers allows the detection of chimerism down to at least $0.1 \%$ of one of the alleles (Figure 2).

This technique will have important applications in the study of murine bone marrow transplantation and transdifferentiation. Although other methods exist to trace the origin of different tissues in transplanted animals (15), several experiments have been performed to date using CD45 mismatched bone marrow transplants. Some of these animals are still available, and our technique will allow investigation of the origin of cells present in non-hematopoietic tissues. A potential caveat is the ubiquitous presence of blood in every organ, which may contaminate the genomic DNA isolated from different tissues. However, perfusing organs with saline before harvesting tissue for DNA isolation may minimize this problem. Also, if the degree of engraftment is below the sensitivity threshold of our method, then other approaches such as immunohistochemical procedures will have to be considered.

Another use for our technique will be the study of colonies generated in vitro by the mixture of two cell types, such as stem cell populations isolated from liver and bone marrow. Colonies with different morphologies (hematopoietic or hepatic) may be obtained under these conditions, and it will be possible to investigate if these colonies have contribution from different tissues (liver or bone marrow) as long as each original population has been isolated from animals with a different CD45 allele.

Our method will also be of use for confirming low-level engraftment of donor cells, such as that one would expect from single-cell transplants. The usual dispersion of fluorescence levels obtained with antibody staining of peripheral blood during flow cytometry can make it difficult to ascertain en- graftment levels less than $1 \%$. The procedures that we describe here may be more sensitive and specific than flow cytometry in this setting and can at least be used as a confirmatory method.

Finally, our technique also constitutes a rapid method to genotype different strains of mice. This is helpful both to confirm which CD45 allele an animal possesses and to ensure backcrossing attempts have been successful.

\section{ACKNOWLEDGMENTS}

Supported in part by National Institutes of Health grant no. RO1 DK58192-01. M.A.G. is a scholar of the Leukemia and Lymphoma Society.

\section{REFERENCES}

1.Brazelton, T.R., F.M. Rossi, G.I. Keshet, and H.M. Blau. 2000. From marrow to brain expression of neuronal phenotypes in adult mice. Science 290:1775-1779.

2.Ferrari, G., G. Cusella-De Angelis, M. Coletta, E. Paolucci, A. Stornaiuolo, G. Cossu, and F. Mavilio. 1998. Muscle regeneration by bone marrow-derived myogenic progenitors Science 279:1528-1530.

3.Irie-Sasaki, J., T. Sasaki, W. Matsumoto, A. Opavsky, M. Cheng, G. Welstead, E. Griffiths, C. Krawczyk, et al. 2001. CD45 is a JAK phosphatase and negatively regulates cytokine receptor signalling. Nature 409:349354.

4.Jackson, K.A., S.M. Majka, H. Wang, J. Pocius, C.J. Hartley, M.W. Majesky, M.L. Entman, L.H. Michael, et al. 2001. Regeneration of ischemic cardiac muscle and vascular endothelium by adult stem cells. J. Clin. Invest. 107:1395-1402.

5.Komuro, K., K. Itakura, E.A. Boyse, and M. John. 1975. Ly-5: a new T-lymphocyte antigen system. Immunogenetics 1:452-456.

6.Krause, D.S., N.D. Theise, M.I. Collector, O. Henegariu, S. Hwang, R. Gardner, S. Neutzel, and S.J. Sharkis. 2001. Multi-organ, multi-lineage engraftment by a single bone marrow-derived stem cell. Cell 105:369377.

7.Lagasse, E., H. Connors, M. Al-Dhalimy, M. Reitsma, M. Dohse, L. Osborne, X Wang, M. Finegold, et al. 2000. Purified hematopoietic stem cells can differentiate into hepatocytes in vivo. Nat. Med. 6:1229-1234.

8.Mezey, E., K.J. Chandross, G. Harta, R.A. Maki, and S.R. McKercher. 2000. Turning blood into brain: cells bearing neuronal antigens generated in vivo from bone marrow. Science 290:1779-1782.

9.Morse, H.C., III, F.W. Shen, and U. Hammerling. 1987. Genetic nomenclature for loci controlling mouse lymphocyte antigens. Immunogenetics 25:71-78.
10.Penninger, J.M., J. Irie-Sasaki, T. Sasaki, and A.J. Oliveira-dos-Santos. 2001. CD45: new jobs for an old acquaintance. Nat. Immunol. 2:389-396.

11.Saga, Y., J.S. Lee, C. Saraiya, and E.A. Boyse. 1990. Regulation of alternative splicing in the generation of isoforms of the mouse Ly-5 (CD45) glycoprotein. Proc. Natl. Acad. Sci. USA 87:3728-3732.

12.Saga, Y., J.S. Tung, F.W. Shen, and E.A. Boyse. 1987. Alternative use of $5^{\prime}$ exons in the specification of Ly-5 isoforms distinguishing hematopoietic cell lineages. Proc. Natl. Acad. Sci. USA 84:5364-5368.

13.Saga, Y., J.S. Tung, F.W. Shen, T.C. Pancoast, and E.A. Boyse. 1988. Organization of the Ly-5 gene. Mol. Cell Biol. 8:4889-4895.

14.Shen, F.W., Y. Saga, G. Litman, G. Freeman, J.S. Tung, H. Cantor, and E.A. Boyse. 1985. Cloning of Ly-5 cDNA. Proc. Natl. Acad. Sci. USA 82:7360-7363.

15.Wulf, G.G., K.A. Jackson, and M.A. Goodell. 2001. Somatic stem cell plasticity: current evidence and emerging concepts. Exp. Hematol. 29:1361-1370.

16.Zebedee, S.L., D. Barritt, R. Epstein, and W.C. Raschke. 1991. Analysis of Ly5 chromosome 1 position using allelic differences and recombinant inbred mice. Eur. J. Immunogenet. 18:155-163.

17.Zebedee, S.L., D.S. Barritt, and W.C. Raschke. 1991. Comparison of mouse Ly5a and Ly5b leucocyte common antigen alleles. Dev. Immunol. 1:243-254.

Received 1 April 2002; accepted 26 August 2002.

\section{Address correspondence to:}

Dr. Margaret A. Goodell

Baylor College of Medicine

One Baylor Plaza N1030

Houston, TX 77030, USA

e-mail: goodell@bcm.tmc.edu 